\title{
SEISMOLOGICAL INVESTIGATION AT MEKAAD RADWAN OTTOMAN PERIOD- CAIRO-EGYPT ${ }^{\text {(a) }}$
}

\author{
Fouad, M. ${ }^{1}$, Mohamed, A. ${ }^{2}$, Salah, H. $^{2}$, Khalil, A. ${ }^{3}$ \& Abd El Hafez, M. ${ }^{1}$ \\ ${ }^{1}$ Conservation dept., Faculty of Archaeology, Cairo Univ., Giza, Egypt \\ ${ }^{2}$ National Research Institute of Astronomy \& Geophysics (NRIAG), Helwan, Egypt \\ ${ }^{3}$ Geology dept., Faculty of Science, Helwan Univ., Helwan, Egypt \\ E-mail: monalyeg@yahoo.com
}

\begin{abstract}
Earthquakes are generally considered the most dangerous factor affecting the historical buildings. The present study is focusing on the determination of the effects of earthquake activities on the historical site of Mekaad Radwan Compound near outskirt of old Fatimid Cairo, the area of Bab Zwiela "Bawabat El Metwali". The analysis of the seismicity data around the site under investigation is carried out to define the design or credible earthquake. In order to achieve the scientific, practical works; seismotectonics, Simulation of earthquake ground motion in the site and site response are studied. The deterministic and probabilistic approaches were carried out showing that the credible earthquake may be located at the same seismic zone of Cairo 1992 earthquake.
\end{abstract}

Keywords: Earthquake, Mekaad Radwan, Parameters, Seismotectonics

\section{Introduction}

Earthquake activity in Egypt is generally termed as moderate. Most of the active zones are lying near the coast, especially at the north eastern part of the country (i.e. the gulfs of Suez and Aqaba). The largest recorded events occurred there with magnitudes approaching 7 . In 1969, an earthquake from the Gulf of Suez shocked the Egyptian territories with magnitude equal to 7. The casualties occurred near Hurghada and south Sinai, while the felt area extended to Cairo with minor damages. The gulf of Aqaba, on the other hand, produced the largest earthquake in the Egyptian history on $22^{\text {nd }}$ November, 1995. The magnitude of the event was 7.2. Fortunately the epicenter was so far from the dense populated areas and hence, the damages were limited in the Egyptian territories. In addition to these high active zones, there exist moderate active zones to the south west of Cairo, to the east of the Nile Delta (Cairo-Suez District), south western desert, and Upper Egypt. Among these seismic zones mentioned, the seismic zone to the south west of Cairo has the largest damaging potentials on the site of Interest. In addition to the local seismic zones, the eastern Mediterranean earthquake activity has unexpectedly high damaging potentials on Lower Egypt (i.e. Nile Delta and Cairo). In 1303, large earthquake in the East Mediterranean caused 
widespread damages to the surrounding countries including Egypt. Heavy damages were reported in the Nile Delta and Cairo [1]. Before and after

\section{Materials and Methods}

This study includes the area that located at the outskirts of the Fatimid Cairo, fig. (1-a, b). As mentioned above, the present work is focusing on the determination of the effects of earthquake activities on the monumental site of Mekaad Radwan Compound near outskirt of Old Fatimid Cairo. The study includes four important points to follow in order to achieve the desired goals. The first point is the building of seismic (earthquake) catalogue near the site of interest. The word near mean all events to a distance of about 80 kilometers and those events with magnitudes above 4.5

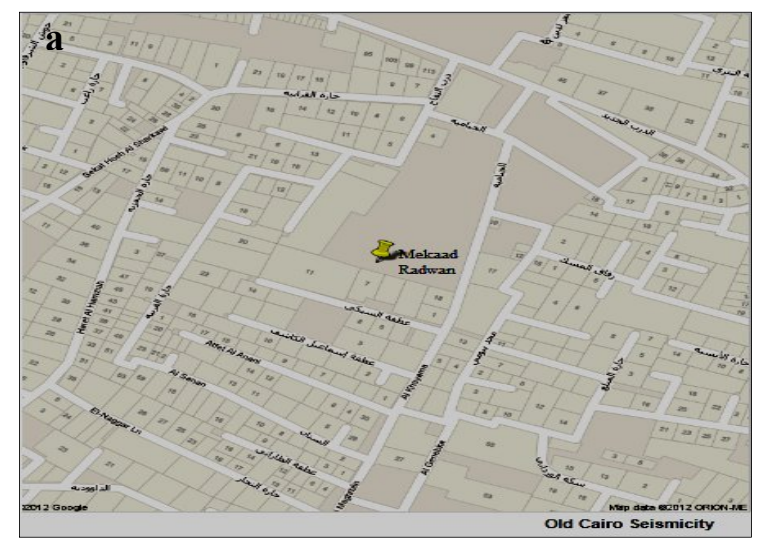

Figure (1) $\underline{\mathbf{a}}$. Location of the site under investigation, $\underline{\mathbf{b}}$. general overview of the site cracks and damages in walls and wooden elements, Mekaad Radwan, Ottoman period, Cairo, Egypt

\section{Results}

\subsection{Seismicity}

The seismotectonics of Egypt are mainly related to the regional tectonics of the Red Sea and Mediterranean one. The active tectonic zones were and still in focus of several seismologists due to the development plans carried out in the country. The space distribution of the epicenters yields a delineation of the active tectonic province as follow: 1) Red Sea, Gulf of Suez, province, with evidences this event many earthquakes from the east Mediterranean were reported to affect Lower Egypt.

to a distance of about 350 kilometers from the site. The catalogue will include both historical (before 1900) and recent (after 1900) earthquakes. The next point is the determination of the design or credible earthquake that will be used to find the maximum ground motion expected in the vicinity of the monumental site. Afterwards, the third point will be the simulation of strong ground motion at site. Finally, site response (resonance and amplification) will be estimated and incorporated with the simulated strong motion to define the due to the credible earthquake.

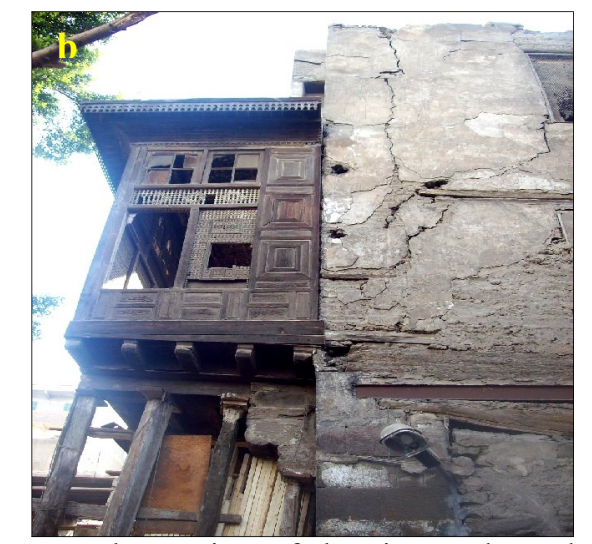
expected dynamic effects on the site of repeated activities along the socalled Clysmic trend. 2) Levant-Aqaba Trend. 3) The Nile delta province between the Pellusic line and Wadi Natrun fault including the Mediterranean Zone. 4) Cairo-Fayoum province, where earthquakes are occasionally very damaging. 5) Kalabsha-Lake Nasser province. 6) East Mediterranean trend. In addition, other areas with remarkable seismic activity do exist such as 
Gaghboub-Siwa and Gilf - ElkebirBahariya zone in the western desert, and Abu dabbab, Hurghada-Wadi Qena and Wadi Hagoul zones in the eastern desert. Egypt experienced earthquakes throughout its entire history. Most of the seismic activities occur at the north eastern part of the country. The hottest seismological regions are the Gulf of Suez and the Gulf of Aqaba. At earlier days of the last century, most of the attention was given to the seismic activities of the Gulf of Suez. The interest was initiated by the occurrence of Shedwan earthquake on March $31^{\text {st }}$, 1969 with magnitude of 6.9. This earthquake was considered as the largest earthquake to hit the Egyptian territories till the year 1995. The location of this event took place at the entrance of the Gulf of Suez near Shedwan Island. The damages encountered due to this event were focused on the nearby areas at Hurghada and south Sinai. With this large magnitude, the earthquake was felt at great distances with reported minor damages to old building in Cairo. The Gulf of Suez region is still tectonically active as proven from earthquake activities there. On November $22^{\text {nd }}, 1995$, the largest reported earthquake shocked the Egyptian territories near the city of Nuweiba at south Sinai. The magnitude of such event was 7.2. The damages encountered due to this event was restricted to cities in its vicinity namely
Nuweiba, Aqaba, Haql ...etc. Most of the damages were reported in the neighboring countries. The event was felt all over the region reaching as far as Lebanon. The seismic activities in this zone are related to the tectonic activities there, as it is well known that the Gulf of Aqaba is the northern continuation of the Red Sea. In addition to the above zones other seismic activities were reported at south west Cairo (Dahshour area), east Cairo (Belbeis, Khankah, and Abu Zaabal), offshore Mediterranean, and an isolated seismic activities at Wadi Hagol. The most damaging earthquake that took place in Egypt is the Cairo earthquake in 19992 despite the fact that the magnitude of this event is moderate. The magnitudes of the earthquakes that occur in other places like Belbeis, Abu Zaabal, El Khanka, and Wadi Hagol seldom exceed the magnitude of 4.5. Other seismic zones are also present but its effects are negligible on the site due to both its long distances and magnitude levels. As an example of such zones are the activities at Aswan and Offshore Mediterranean. The location of the epicenters of the instrumental seismicity is shown in fig. $(2-a, b)$. In addition to this, the historical data indicate that some events took place at both sharqiya province and east Cairo. The Magnitudes of these events are about 5.5 [2]. A map showing the distribution of historical earthquakes in Egypt is shown in fig. (2-c).
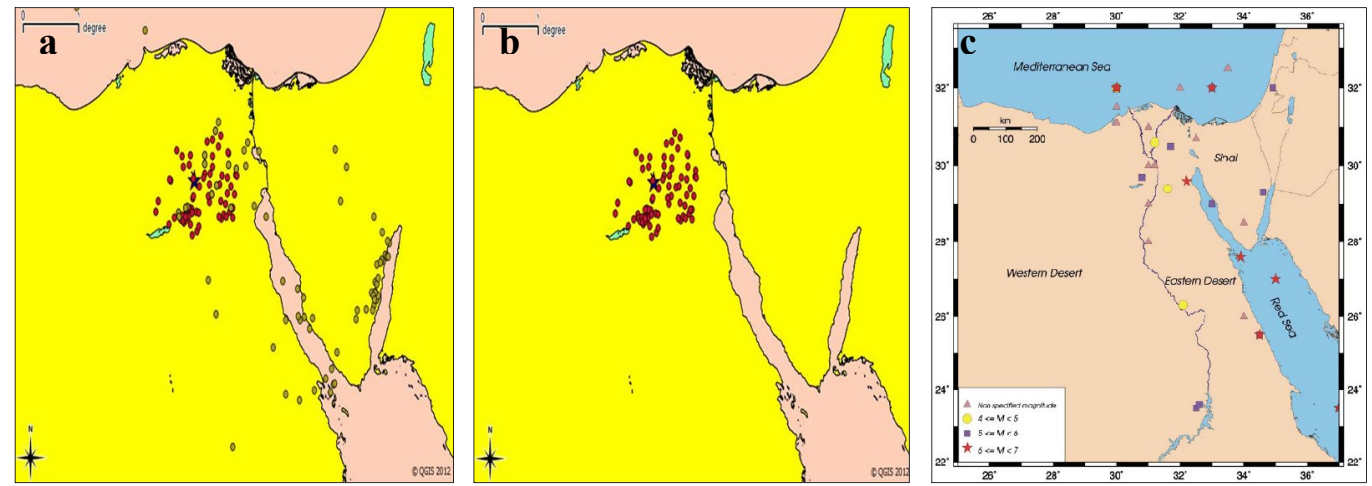

Figure (2) a. Seismicity with magnitudes larger than 4.5 to a distance of $350 \mathrm{Km}$. from the site, $\underline{\mathbf{b}}$. seismicity to a distance $80 \mathrm{Km}$. from the site, $\underline{\mathbf{c}}$. map showing the historical earthquakes in Egypt, (after NRIAG, 2004). 
The analysis of the seismicity data around the site under investigation is carried out to define the design or credible earthquake. The design earthquake is a term representing the largest earthquake and/or ground acceleration expected to struck the site over a certain time window. The approaches used to define the credible earthquake may be classified into deterministic and probabilistic. The deterministic one inspects the seismic history around the site to pick the largest reported event in the catalogue. This event is termed as credible earthquake and certain increment is added to its magnitude as a safety factor. In general, the increment equals 0.5 . The probabilistic method, on the other hand, applies probabilistic model to predict the largest future earthquake. Deif and Khalil [3] applied both techniques and yielded that the credible earthquake for the region is the Cairo earthquake that occurred on $12^{\text {th }}$ October, 1992. The magnitude of the event was 5.8, thus according to the

\subsection{Simulation of earthquake ground motion at the site}

Simulation of earthquake ground motion (acceleration time history) means the virtual recording of earthq-uake ground motion due to the design or credible earthquake at the site of interest. The simulation method that will be adopted here is the stochastic technique. The method makes use of randomized approach to simulate the high frequency form of the accelerogram. The technique generally pays little attention towards the physical interpretation of the waveform. Instead it relies on the overall feature of the accelerogram. In general, the method model or simulate the high frequency ground motion using band limited Gaussian noise in which the radiated energy is distributed over specific duration. Atkinson and Somerville gave a brief explanation of technique [4]. The procedure is applied firstly in the time domain starting by the deterministic approach the magnitude of the credible earthquake will be $5.8+$ 0.5 , which equals 6.3 in magnitudes. The probabilistic method, on the other hand, yielded a maximum magnitude 6.1. Thus, for safety reason a magnitude of 6.3 is chosen for the credible earthquake that may occur at the same geographic region as Cairo earthquake. The epicenter distance between the epicenter of Cairo earthquake and Mekaad Radwan compound is about 33 $\mathrm{km}$. The peak ground acceleration is estimated using the relation of Deif and Khalil. The relation is defined as: $\log \left(a_{h}\right)=-1.382+0.334 M s-1.128 \log { }^{\circledR}-$ $\mathbf{0 . 0 0 0 5} \boldsymbol{R}$. Where $\left(\mathbf{a}_{\mathbf{h}}\right)$ is the peak horizontal acceleration, (Ms) is the surface wave magnitude and $(\mathbf{R})$ is the hypocentral distance. The value of $a_{h}$ estimate is $75 \mathrm{~cm} / \mathrm{s}^{2}$ which is small to moderate values. It is worth to mention here that the effect of site is not encountered in this estimate. Site effect will investigate in forthcoming sections.

generation of windowed time series of band limited white random Gausian noise with zero mean. The generated series is then convolved with the spectrum of scaled seismic source. The result of the convolution is transformed back to the time domain. In applying the technique, the attenuation to ground motion with distance is described by empirical relation. The simulation software used is SMSIM [5]. The source parameters used as input is the same as those used for peak ground acceleration estimated earlier. The simulated time series is shown in fig. (3-a). In addition to the simulated ground motion the software offer the estimation of the site response spectra due to the simulated ground acceleration. The acceleration response spectra PSA is shown in fig. (3-b). The simulation results show that the peak ground acceleration is about $60 \mathrm{~cm} / \mathrm{s}^{2}$ which are somehow consistent with the result obtained from Deif and Khalil. 

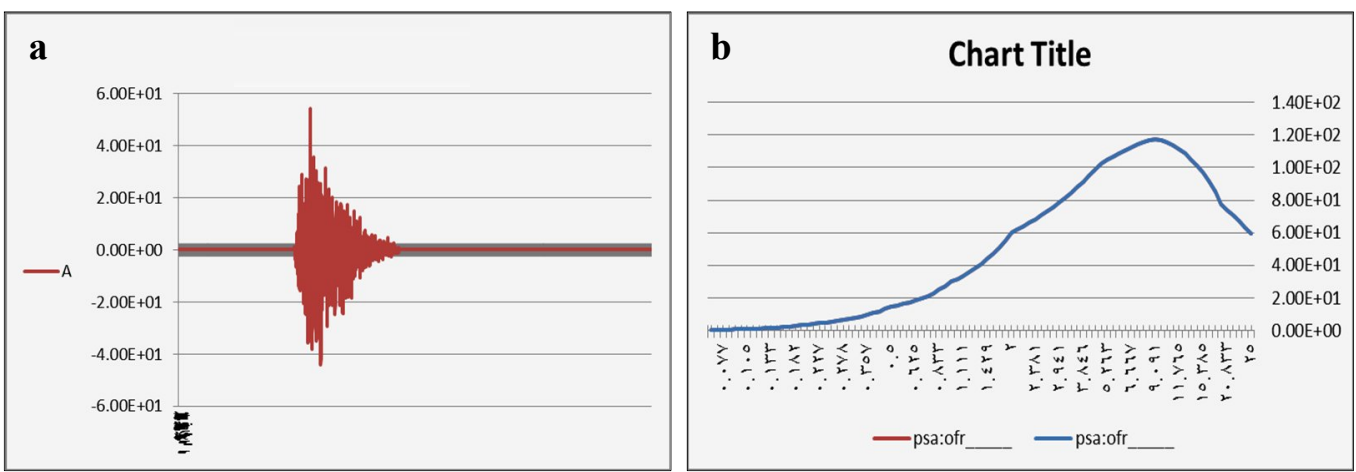

Figure (3) a. Simulated ground acceleration time series (accelerogram) using SMSIM software, $\underline{\mathbf{b}}$. response spectra using the simulated time series at damping ratio of 0.05 .

\section{Discussion}

The site response plays the major effects on the severity and frequency content of earthquake ground vibration at a site. It is observed that alluvial deposits may result in high amplification to ground motion which may result in unexpected high damages. The earthquake of Mexico City in 1985 is a classical example for that situation. Accordingly many investigators in the last two decades were interested in measuring such effect. The site response in the present study is carried out using the tri-axial recording of ambient noise at the site. The recordings are used to define the site response using the so called $\mathrm{H} / \mathrm{V}$ method. The $\mathrm{H} / \mathrm{V}$ method is widely used to define the dynamic characteristics of the site [6]. The method depends on the use of ambient noise recordings at a site to determine both the amplification and fundamental natural frequency of the site. Spectral ratio means the division of the spectrum of the horizontal component (either the E-W or N-S or the net of both) by the spectrum of the vertical component. The ambient seismic noise is a low amplitude soil vibration, which resulted from complex distribution of both natural and man-made sources. These sources may be of industrial origin or natural phenomena, such as wind action and microseisms. Such situation is usually modeled as random distribution

of surface wave sources randomly distributed along the earth's surface. A method which employs microtremor has been introduced for estimating dynamic characteristics of surface layers, in early 1950 . Then usage of this method has received lots of criticism considering uncertainty about the source of microtremor. After an introduction of the Nakamura's technique (H/V or QTS technique) many people have paid a renewed great attention for estimating dynamic characteristics of ground and structures using microtremor, since clear and reliable information was provided by very simple and inexpensive noise measurements [7]. $\mathrm{H} / \mathrm{V}$ technique was developed by Nakamura with relating borehole investigations together with strong motion records analysis, on the various geological site conditions. It was hypothesized that the vertical component of ambient noise keeps the characteristics of source to sediments surface ground, is relatively influenced by Rayleigh wave on the sediments and can therefore be used to remove both of the source and the Rayleigh wave effects from the horizontal components. It is effective to identify the fundamental resonant frequency of a sedimentary layer, with implied amplification factors that are more realistic than those obtained from sediment to rock site ratios. It has been shown by many 
researchers (ex. Ohmachi et. al., 1991; Lermo et. al., 1992; Field and Jacob, 1993, 1995) that how such $\mathrm{H} / \mathrm{V}$ ratio of noise can be used to identify the fundamental resonant frequency and

(1) $H_{f}=A_{h}{ }^{*} H_{b}+H_{s} \quad V_{f}=A_{v}{ }^{*} V_{b}+V_{s}$

Where $\left(\mathbf{A}_{\mathbf{h}}\right)$ and $\left(\mathbf{A}_{\mathbf{v}}\right)$ are amplification factor of horizontal and vertical motions of vertically incident body wave. (Hb) and ( $\mathbf{V b})$ are spectra of horizontal and vertical motion in the basement under the basin (outcropped basin). Hs and Vs are spectra of horizontal and vertical directions of Rayleigh waves. $T_{h}$ and $T_{v}$ are amplification factor of horizontal and vertical motion of surface sedimentary ground based on seismic motion on the exposed rock ground near the basin. In

$$
T_{h}^{+}=\frac{T_{h}}{T_{v}}=\frac{\frac{H_{f}}{V_{f}}}{\frac{H_{b}}{V_{b}}}=\frac{Q T S}{\frac{H_{b}}{V_{b}}}=\frac{\left[A_{h}+\frac{H_{s}}{H_{b}}\right]}{\left[A_{v}+\frac{V_{s}}{V_{b}}\right]}
$$

In equation $(4), \mathrm{H}_{\mathrm{b}} / \mathrm{V}_{\mathrm{b}} \approx 1$. $\mathrm{H}_{\mathrm{s}} / \mathrm{H}_{\mathrm{b}}$ and $\mathrm{V}_{\mathrm{s}} / \mathrm{V}_{\mathrm{b}}$ are related with the route of energy of Rayleigh waves. If there is no influence of Rayleigh wave, $\mathrm{QTS}=\mathrm{A}_{\mathrm{h}} / \mathrm{A}_{\mathrm{v}}$. If amount of Rayleigh wave is high, then second term in above formulation gets dominant and QTS = $\mathrm{H}_{\mathrm{S}} / \mathrm{V}_{\mathrm{s}}$ and the lowest peak frequency of $\mathrm{H}_{\mathrm{s}} / \mathrm{V}_{\mathrm{s}}$ is nearly equal to the lowest proper frequency $F_{o}$ of $A h$, see fig. (3b). In the range of $F_{o}, A_{v}=1$. QTS shows stable peak at frequency $F_{0}$. Even when influence of Rayleigh wave is large, Vs become small (which results in a peak of $\mathrm{Hs} / \mathrm{Vs}$ ) around the first order proper frequency due to the multiple reflections of horizontal motions. Also, QTS $=A_{h}$, if microtremors of the basement $\mathrm{V}_{\mathrm{b}}$ is relatively large comparing to the Rayleigh wave. Briefly, QTS represents the first order proper frequency due to multiple reflection of $\mathrm{SH}$ wave in the surface ground layer and resulted amplification factor, regardless of the influence degree amplification factor of sediments. Horizontal and vertical spectra on the surface ground of the sedimentary basin $\left(\mathrm{H}_{\mathrm{f}}, \mathrm{V}_{\mathrm{f}}\right)$ can be written as follows:

$$
\begin{array}{ll}
T_{h}=\frac{H_{f}}{H_{b}} & \mathrm{~T}_{\mathrm{v}}=\frac{V_{f}}{V_{b}}
\end{array}
$$

general, $\mathrm{P}$ wave velocity is more than three-four times of $S$ wave velocity. In such sedimentary layer, vertical component cannot be amplified $\left(A_{v}=1\right)$ around the frequency range where horizontal component receives large amplification. If there is no effect of Rayleigh waves, $\mathrm{V}_{\mathrm{f}} \approx \mathrm{V}_{\mathrm{b}}$. On the other hand, if $\mathrm{V}_{\mathrm{f}}$ is larger than $\mathrm{V}_{\mathrm{b}}$, it is considered as the effect of surface waves. Then estimating the effect of Rayleigh waves by $\mathrm{V}_{\mathrm{f}} / \mathrm{V}_{\mathrm{b}}$ $\left(=\mathrm{T}_{\mathrm{v}}\right)$, horizontal amplification can be written as:

$$
\text { where, } Q T S=\frac{H_{f}}{V_{f}}=\frac{A_{h}{ }^{*} H_{b}+H_{s}}{A_{v}{ }^{*} V_{b}+V_{s}}=\frac{H_{b}}{V_{b}} \cdot \frac{\left\lfloor A_{h}+\frac{H_{s}}{H_{b}}\right\rfloor}{\left[A_{v}+\frac{V_{s}}{V_{b}}\right]}
$$

of Rayleigh waves. Detailed explanations of the method may be found in Nakamura 1996, 2000. The ambient noise was recorded at the site of Radawan compound at the outskirts of Fatimid Cairo. Five records were obtained at sample frequency of $100 \mathrm{sps}$ for about 10 minutes for each record. The measuring instrument is K2-Altus accelerograph, fig. (4-a). The instrument is equipped with three components sensor for measuring strong ground motion with high precision. In addition fig. (4-b, c) document the field operations. The recordings were carried out on the soil in front of the house and on the first level of the house. The recordings were analyzed using Geopsy and SESAME software. The results of the analysis are shown in fig. $(5-a, b)$, where fig. (5-a) represents the resonance frequency and amplification on the soil, while fig. (5-b) represents the situation at the first level of the house. 

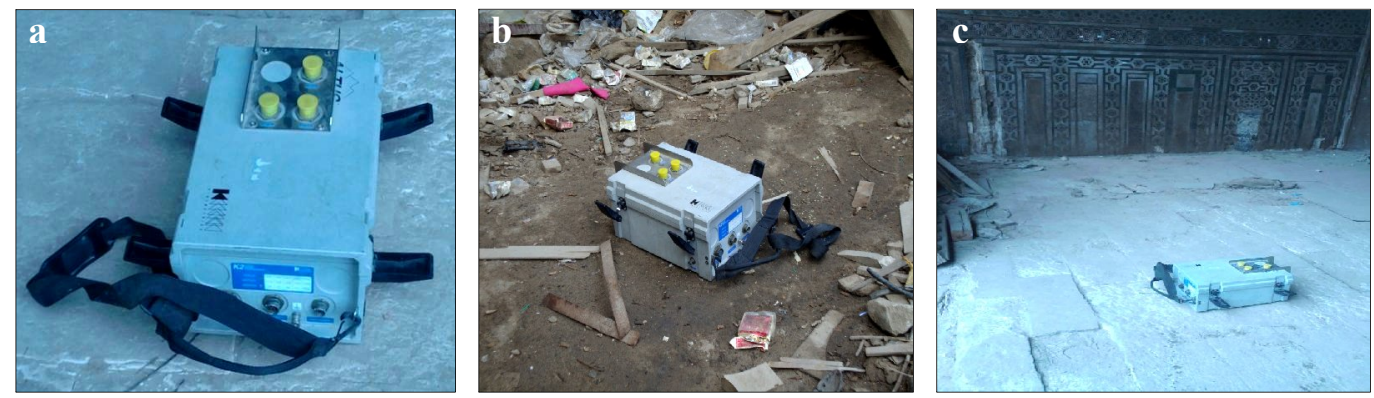

Figure (4) a. K2 Altus accelerograph used to record the ambient noise of the present work, $\underline{\mathbf{b}}$. recording at the soil in front of Mekaad Radwan, $\underline{\mathbf{c}}$. recording at first level of Mekaad Radwan
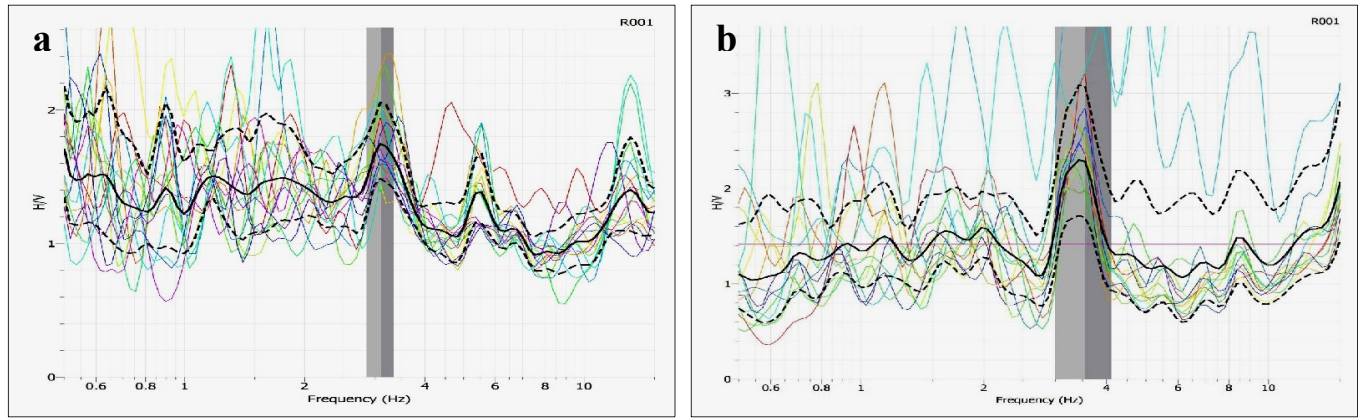

Figure (5) a $\mathrm{H} / \mathrm{V}$ ratio curves at the soil. From the solid black curve the resonance frequency is 3 and the amplification is just below 2 , $\underline{\mathbf{b}} \mathrm{H} / \mathrm{V}$ curves at the first level. The resonance frequency is shifted to about $3.6 \mathrm{~Hz}$

\section{Conclusion}

Seismological study is carried at Mekaad Radwan compound to investigate the effect of earthquakes on the site. The starting point to the work was to collect the historical and instrumental seismicity around the site under investigation in order to determine the credible or design earthquake. Deterministic and probabilistic approaches were carried out showing that the credible earthquake may be located at the same seismic zone of Cairo 1992 earthquake. The magnitude of this earthquake is estimated to be 6.3. The peak ground acceleration were thus estimated using the relation of Deif and Khali 2002, reaching the value of $75 \mathrm{~cm} / \mathrm{s}^{2}$. The next step was to simulate the ground motion time history at the site during the credible earthquake. Stochastic method was used for the simulation procedure employing SMSIM software of Boore 2009. The maximum amplitude of the time series is about $60 \mathrm{~cm} / \mathrm{s}^{2}$ which fairly agree with the peak ground acceleration estimated earlier. The final step was to define the resonance frequency and amplification of the ground and the first level of the structure. These parameters were obtained using the spectral ratio method which depends on dividing the spectrum of the horizontal component by the spectrum of the vertical component. The result show that the resonance frequency 3 and $3.6 \mathrm{~Hz}$ for the soil and first level of the house respectively. The amplification on the other hand was also increased by one.

\section{Endnotes}

(a) This research is a part of NIKER PROJECT $\mathrm{N}^{\circ}$ : 244123 FP7 (NEW INTEGRATED KNOWLEDGE BASED APPROACHES TO THE PROTECTION OF CULTURAL HERITAGE FROM EARTHQUAKE-INDUCED RISK).

\section{References}

[1] Ambraseys, N., Melville, C. \& Adam, R., (1994). The seismicity of Egypt, Arabia and the Red Sea: A

EU Coordinator: Padova University (Italy). CDCU coordinator: Prof. Dr. Mona Fouad, Cairo University Faculty of Archaeology - Conservation Department

Historical Review, Cambridge Univ. Press, London.

[2] Khalil, A., (1998). Strong motion St- 
udies at the monumental areas of Egypt, PhD., Geology dept., Faculty of Sciences, Ain Shams Univ.

[3] Deif, A. \& Khalil, A. E., (2002). Seismic hazard assessments at Sphinx, Egypt, JPME, Vol.5 (1), pp.117129.

[4] Atkinson, G. \& Sommerville, P., (1994). Calibration of time history simulation methods. BSSA, Vol. 84, pp. 400-414.

[5] Boore, D., (2009). Comparing stochastic point-source and finite source ground-motion simulations: SMSIM and EXSIM, BSSA, Vol. 99, pp. 3202-3216.

[6] Nakamura, Y. (1996). Real time information systems for seismic hazards mitigation UrEDAS, HERAS and PIC, Quarterly Report of RTRI, Vol. 37 (3), pp. 112-127.

[7] Nakamura, Y. (2000). Clear identification of fundamental idea of Nakamura's technique and its applications, Vol. 2, New Zeland National Society for Earthquake engineering (eds.), 12 WCEE, Paper Ref., 2656, Auckland, New Zeland, pp. 1-8 